Rev Biomed 2002; 13:9-13.

\title{
Frecuencia de seropositividad para Chlamydia pneumoniae en adultos de Yucatán, México.
}

\author{
Artículo Original
}

Bertha Jiménez-Delgadillo, Ignacio Vado-Solís, Hugo Laviada-Molina, Jorge Zavala-Velázquez.

Departamento de Patología Tropical de la Facultad de Medicina de la Universidad Autónoma de Yucatán, Mérida, Yucatán, México.

\section{RESUMEN.}

Introducción. Las infecciones por Chlamydia pneumoniae son causa de enfermedades respiratorias que pueden ir desde la afección poco sintomática de vías respiratorias altas hasta neumonías graves. Esta bacteria intracelular se ha asociado también con enfermedad ateroesclerótica cardiovascular por lo que su estudio epidemiológico ha adquirido mayor interés. El propósito de este estudio fue obtener información preliminar de la frecuencia seroepidemiológica de esta infección en una muestra de la población adulta del estado de Yucatán, México.

Material y métodos. Se procesaron 85 muestras de suero de igual número de sujetos aparentemente sanos de uno y otro sexo, mayores de 20 años de edad, de 52 poblaciones del estado de Yucatán. Se ajustó el número de personas por década de edad y por género para que correspondieran proporcionalmente a la estructura de la población, según las cifras censales oficiales del estado. Se determinó inmunoglobulina A específica ( $\operatorname{Ig} \mathrm{A}$ ) para
Chlamydia pneumoniae por medio de ensayo inmunoenzimático (ELISA).

Resultados. El $40 \%$ de la población estudiada resultó seropositiva. Se encontró una mayor frecuencia en los sujetos más jóvenes del grupo y una tendencia decreciente de la misma en los de mayor edad.

Comentario. Estos datos permiten apreciar en la muestra estudiada de la población de adultos de Yucatán, una frecuencia alta de seropositividad a Chlamydia pneumoniae, similar a la reportada en la literatura en otros países, lo que sugiere que la prevalencia de enfermedades respiratorias producidas por este agente (sintomáticas o asintomáticas) puede ser igualmente alta. Ello adquiere mayor relevancia por la implicación emergente que ese agente infeccioso parece tener como factor asociado a la génesis de la cardiopatía ateroesclerosa. (Rev Biomed 2002; 13:9-13)

Palabras clave: Chlamydia pneumoniae, seroprevalencia, Yucatán, ateroesclerosis.

Solicitud de sobretiros: M. en C. Jorge Zavala-Velázquez, Departamento de Patología Tropical, Facultad de Medicina, Universidad Autónoma de Yucatán. Avenida Itzáes No. 498 x 59 y 59-A, C.P. 97000, Mérida, Yucatán, México. Tel. (999) 928-53-29 y Fax: 924-05-54.

E-mail: hugola@mid.cablered.com.mx

Recibido el 6/Diciembre/2000. Aceptado para publicación el 21/Junio/2001.

Este artículo está disponible en http://www.uady.mx/ biomedic/rb021312.pdf

Vol. 13/No. 1/Enero-Marzo, 2002 
B Jiménez-Delgadillo, I Vado-Solís, H Laviada-Molina, J Zavala-Velázquez.

\section{SUMMARY.}

Frequency of Chlamydia Pneumoniae antibodies in the rural population of Yucatan, Mexico.

Introduction. Chlamydia pneumoniae (CP) respiratory infections produce a wide spectrum of diseases, from almost asymptomatic high respiratory tract affection to serious pneumonia. This intracellular bacterium has also been associated with atheroesclerotic cardiovascular disease, making its epidemiological study more attractive. The aim of this study was to obtain preliminary information of the seroepidemiologic behavior of CP infection in an adult sample from the state of Yucatan, Mexico.

Material and methods. Blood samples were obtained from 85 healthy subjects (42 male, 43 female) over 20 years old. The number of subjects was adjusted by age decades and gender, to be proportionally true to the structure of the population of the region, according to the official statistics of the state. CP specific antibodies IgA were measured by immunoenzimatic assay (ELISA). The blood samples came from 52 diferent settlements of the Yucatan state randomly selected. Results. Among the 85 blood samples, 34 (40\%) were seropositive. There was a higher frequency in the younger subjects sampled and a lower rate in the older, however this trend was not statistically significant.

Discussion. There is a high frequency of seropositivity in the adult population of Yucatan, Mexico, similar to the reported data of the literature in other countries, suggesting also a high prevalence of (symptomatic or asymptomatic) respiratory diseases produced by $\mathrm{CP}$. This high frequency is more relevant as there is mounting evidence to suggest that Chlamydia pneumoniae might play a role in atheroesclerosis.

(Rev Biomed 2002; 13:9-13)

Key words: Chlamydia peumoniae, seroprevalence, Yucatan, atheroesclerosis.

\section{INTRODUCCIÓN.}

Chlamydia pneumoniae (CP), es una bacteria piriforme, gram negativa y es un parásito intracelular obligado. Tiene características distintivas con respecto a $C$. psittaci y $C$. trachomatis aunque comparten un antígeno de grupo o específico del género (1). CP es la designación actual de las cepas que se agrupaban bajo el nombre "TWAR" hasta antes de 1989. Este se acuñó a partir de las iniciales de los laboratorios que obtuvieron los primeros aislados clínicos TW183, de la conjuntiva de un niño sano en 1965, y AR-39, proveniente de un estudiante universitario con faringitis en 1983 (2). Es un patógeno humano que se propaga por contacto personal íntimo. Como agente etiológico se asocia a infecciones de vías respiratorias superiores y hasta a un $10 \%$ de los casos de neumonía adquirida en la comunidad $(3,4)$. Las manifestaciones de infección respiratoria por CP pueden ser desde subclínicas o asintomáticas hasta procesos graves que ponen en peligro la vida. Este espectro clínico incluye neumonías, bronquitis, sinusitis, faringitis y otitis, presentándose sobre todo en adultos jóvenes. Las neumonías son entidades clínicas que afectan más frecuentemente a adultos, y que son más prevalentes conforme avanza la edad.

Sin embargo, una alta proporción (de un 70 a 90\%) de los casos de infecciones por este agente son escasamente sintomáticas o asintomáticas. La seropositividad en muchos grupos de población adulta se acerca al 40\% (3). Los anticuerpos IgA e IgG contra CP son los más ampliamente aceptados como marcadores para infección crónica por este agente.

Desde 1988, más de 20 estudios realizados en diversos países han demostrado la asociación entre la infección crónica por este agente infeccioso y diversas manifestaciones de ateroesclerosis, o con factores de riesgo establecidos como generadores de enfermedad ateroesclerosa $(3,5-7)$, por lo que además de su impacto como causa de patología respiratoria, está por demostrarse plenamente su papel como factor de riesgo cardiovascular. Las

\section{Revista Biomédica}


Seroepidemiología de Chlamydia pneumoniae en Yucatán.

cardiopatías se han instalado como principal causa de muerte en México y en el estado de Yucatán desde hace varios años $(8,9)$. Todo ello justifica el interés por conocer el comportamiento epidemiológico de CP en Latinoamérica y en México, ya que la mayoría de los datos seroepidemiológicos con los que se cuentan provienen de estudios efectuados en Europa, Estados Unidos de América y países asiáticos. El objetivo de este trabajo es presentar un reporte de la frecuencia de seropositividad de IgA para CP en población rural del estado de Yucatán.

\section{MATERIAL Y MÉTODOS.}

Se estudiaron sueros almacenados y congelados de sujetos mayores de 20 años de edad, aparentemente sanos, de 52 poblaciones del estado de Yucatán, México. Dichas muestras fueron obtenidas en 1999 para un estudio seroepidemiológico previo, en relación con la frecuencia de infección por leptospira en el área rural de Yucatán (material no publicado).

Se seleccionaron aleatoriamente los sueros y se ajustó su número para que agrupados por décadas correspondieran proporcionalmente a los de la pirámide poblacional según la edad y género, de acuerdo a los datos del Censo Nacional de Población y Vivienda de 1995 en el estado de Yucatán (9). Una vez hecha la selección aleatoria se incluyó un total de 85 sujetos, 42 hombres y 43 mujeres de 20 a 70 años de edad.

Todas las muestras fueron procesadas simultáneamente en el laboratorio del Departamento de Patología Tropical de la Facultad de Medicina de la Universidad Autónoma de Yucatán, usando técnicas estandarizadas. Los sueros se procesaron para cuantificar anticuerpos IgA contra Chlamydia pneumoniae con técnica de ELISA utilizando un equipo comercial de Labsystems, Helsinki, Finlandia. Se utilizaron 10 $\mu \mathrm{L}$ del suero de cada paciente para cada determinación, según la técnica y los parámetros descritos por el fabricante de dicho equipo. Este ensayo no reacciona en forma cruzada con otras especies de Chlamydia.

\section{RESULTADOS.}

Se encontraron 34 casos seropositivos para IgA contra $\mathrm{CP}$, representando una frecuencia porcentual de $40 \%$ con respecto al número total de sueros de pacientes seleccionados para integrar la muestra. Los casos positivos provinieron de 27 diferentes poblaciones. Al determinar el porcentaje de casos positivos por edad, calculándose proporcionalmente del total de positivos por cada una de las décadas, se observó una tendencia decreciente de casos positivos conforme avanza la edad (figura 1). Sin embargo al comparar estadísticamente los diferentes grupos de edad la prueba de $x^{2}$ estas diferencias resultaron estadísticamente insignificantes ( $p>0.05)$, quizá por el reducido tamaño de la muestra.

El número de sueros de pacientes positivos por edad y sexo se describe en el cuadro 1 . Se analizó si hubo algún predominio de casos de acuerdo a la población de los municipios (por ejemplo: en localidades de menos o más de 2500 habitantes; o bien menos o más de 5000 habitantes) en donde se encontraron los casos positivos, o bien de acuerdo a la zona geográfica de las diversas localidades incluidas, no encontrando diferencias relevantes ya sea por número de habitantes como tampoco por zonas geográficas en las que se divide al estado de Yucatán, México de acuerdo a su actividad económica, pecuaria o agrícola predominante.

\section{DISCUSIÓN.}

Los resultados de este estudio muestran que la frecuencia de seropositividad para anticuerpos IgA como marcador de infección crónica por $\mathrm{CP}$ es similar a lo reportado en otras regiones del mundo, con cifras cercanas a un $40 \%$ de las poblaciones abiertas evaluadas. Esto demuestra, de acuerdo a los objetivos de este trabajo, que esta 
B Jiménez-Delgadillo, I Vado-Solís, H Laviada-Molina, J Zavala-Velázquez.

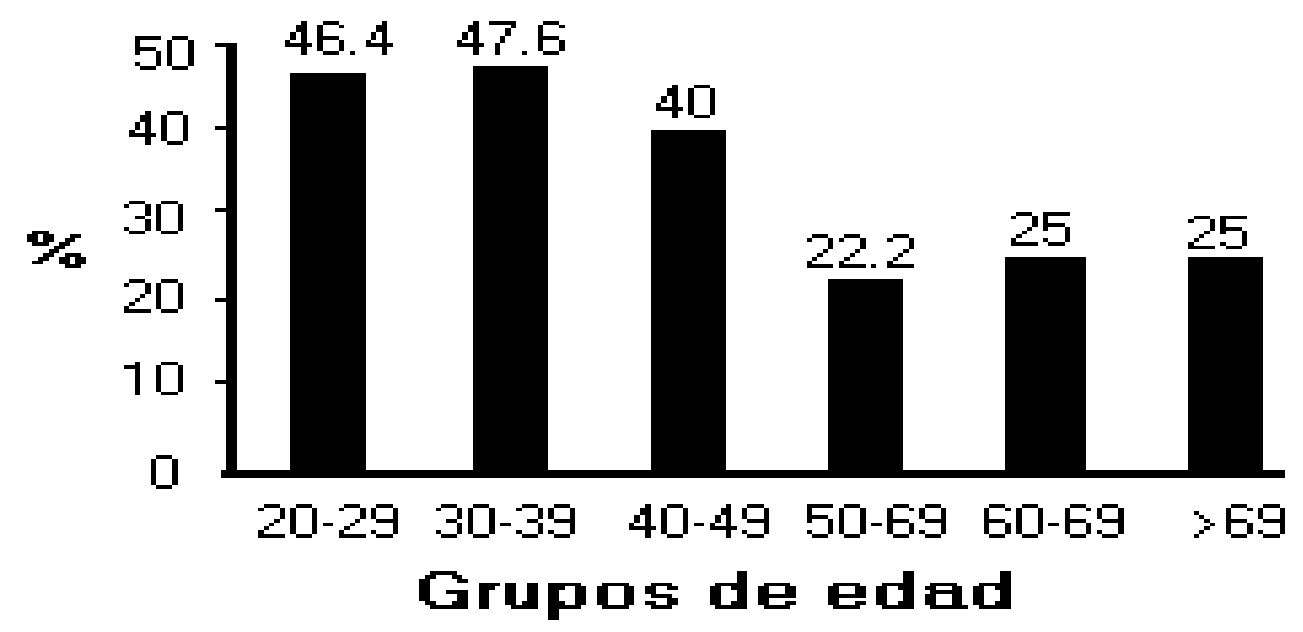

Figura 1.- Frecuencia porcentual por décadas de edad, de seropositividad para IgA contra Chlamydia pneumoniae.

especie de Chlamydia se encuentra circulando en la población adulta de Yucatán. No se encontró diferencia por género en la frecuencia de casos positivos entre los sueros de los hombres y las mujeres estudiados. Llama la atención la tendencia decreciente que se aprecia en esta población rural conforme avanza la edad de la población. Ello podría explicarse de dos maneras:

1. La determinación de IgA sérica refleja probablemente sólo los casos con infección crónica o reinfección. Si se hubiese determinado $\operatorname{IgG}$ simultáneamente posiblemente se observaría el efecto "acumulativo" de la edad, determinado por

Cuadro 1

Casos positivos por edad y género para la determinación de IgA contra Chlamydia pneumoniae en población rural de Yucatán.

\begin{tabular}{llccc}
\hline $\begin{array}{l}\text { Mujeres } \\
\text { Edad }\end{array}$ & $\begin{array}{c}\text { Hombres } \\
\text { Pos/Total }\end{array}$ & $\begin{array}{c}\text { Ambos } \\
\text { Pos/Total }\end{array}$ & $\begin{array}{c}\% \text { de Pos } \\
\text { (Por década) }\end{array}$ \\
\hline $20-29$ & $6 / 14$ & $7 / 14$ & $13 / 28$ & 46.4 \\
$30-39$ & $5 / 11$ & $5 / 10$ & $10 / 21$ & 47.6 \\
$40-49$ & $4 / 8$ & $2 / 7$ & $6 / 15$ & 40.0 \\
$50-59$ & $1 / 4$ & $1 / 5$ & $2 / 9$ & 22.2 \\
$60-69$ & $1 / 4$ & $1 / 4$ & $2 / 8$ & 25.0 \\
$>69$ & $0 / 2$ & $1 / 2$ & $1 / 4$ & 25.0 \\
\hline Total & $17 / 43$ & $17 / 42$ & $34 / 85$ & $40.0 \%$ \\
\hline
\end{tabular}

Pos= Sueros positivos para IgA contra Chlamydia pneumoniae Revista Biomédica la memoria inmunológica. Las epidemias de neumonía por C. pneumoniae en Finlandia, han permitido un estudio detallado de su comportamiento epidemiológico y clínico $(2,5)$. A partir de ello se ha determinado un comportamiento serológico distinto entre los primeros episodios y las reinfecciones. La respuesta inicial en los individuos con un primer episodio, consiste en la elevación de la fracción IgM, aproximadamente tres semanas después de iniciado el cuadro clínico. Seguidamente, se produce una elevación de la fracción IgG unas 6 a 8 semanas después del inicio de los síntomas, la cual persiste por varios meses. La fracción IgA mostraba elevaciones mínimas o ausentes. En las reinfecciones, por el contrario la elevación de anticuerpos ocurre a expensas de las fracciones $\operatorname{IgG}$ o $\operatorname{Ig} \mathrm{A}$, con mínima o nula participación de IgM. En la mayoría de los reportes, la prevalencia de seropositividad aumenta con la edad, cuando se utiliza como marcador IgG (3). Nuestro grupo prefirió realizar este estudio piloto con IgA, en virtud de que es la inmunoglobulina cuya seropositividad para Chlamydia pneumoniae mejor se ha asociado a un mayor riesgo de enfermedad ateroesclerosa coronaria comparada con la IgG $(1,11)$.

2. El decremento de casos positivos al avanzar la edad pudiera asociarse al relativo aislamiento que la senectud impone a los individuos, particularmente en las áreas rurales. Siendo que el 


\section{Seroepidemiología de Chlamydia pneumoniae en Yucatán.}

contagio es de persona a persona, es de suponerse que los jóvenes, más involucrados en actividades comunitarias (escolares, laborales o de cualquier otra índole), están más expuestos al riesgo de reinfección reflejado por los títulos de IgA sérica.

Estos datos preliminares, aún con sus limitaciones, estimulan la posibilidad de estudiar la magnitud del papel de CP como un agente frecuente entre los microorganismos causantes de infecciones respiratorias en México y en particular en Yucatán. Además, los numerosos estudios que sugieren la asociación de infección crónica por $\mathrm{CP}$ con varios factores de riesgo para ateroesclerosis y enfermedad cardiovascular, hacen necesario profundizar en el comportamiento de este microorganismo en la región, ya que en Yucatán, desde 1990 las enfermedades del corazón tienen el primer lugar como causa de muerte en la población adulta, mientras que los accidentes cerebrovasculares ocupan a partir de 1993, el tercero $(8,12)$. La obesidad, las dislipidemias, la hipertensión y la diabetes mellitus, que son factores de riesgo para el desarrollo de las enfermedades ateroesclerosas del corazón y cerebrovascular, también son frecuentes en la población adulta de esta región (12-15), que pudiesen estar interactuando con otros factores ambientales tales como la infección por CP.

\section{REFERENCIAS.}

1.- Kuo C, Grayston T. Factors afecting viability and growth in He La 229 cells of chlamydia sp. strain TWAR. J Clin Microbiol 1988; 26 : 812-5.

2.- Grayston JT, Campbell LA, LA, Kuo CC. A new respiratory patogen: Chlamydia pneumoniae strain TWAR. J Infect Dis 1990; 161: 618-25.

3.- Saiku P. Epidemiology of Chlamydia pneumoniae in atheroesclerosis. Am Heart J 1999; 138: 500-3.

4.- Stamm W. Infecciones por Chlamydia. En: Fauci AS, Braunwald E, Isselbachor KJ, Wilson JD, Martin JB, Kasper DL, Hauser SL, Longo DL, editores. Harrison. Principios de Medicina Interna, $14^{\text {th }}$ edición, México: McGraw-Hill Interamericana; 1999. p. 1209-19.
5.- Kleemola M, Saikku P, Visacorpi R, Wang SP, Grayston JT. Epidemics of pneumonia caused by TWAR, a new Chlamydia organism, in military trainees in Finland. J Infect Dis 1985; 151: 230-6.

6.- Muhlestein J. Chronic infection and coronary artery disease. Science \& Medicine 1998; Nov-Dec: 16-25.

7.- Wong YK, Gallagher PJ, Ward ME. Chlamydia pneumoniae and atheroesclerosis. Heart 1999; 81: 232-8.

8.- Dirección General de Estadística, Informática y Evaluación, Secretaría de Salud. México: SSA; 1997.

9.- Instituto Nacional de Estadística, Geografía e Informática. Yucatán. Conteo de Población y Vivienda. México: INEGI; 1995.

10.- Leowattana W, Mahanonda N, Bhuripunyo K, Leelarasamee A, Pokum S, Suwimol B. The prevalence of Chlamydia pneumoniae antibodies in Thai patients with coronary artery disease. J Med Assoc Thai 1999; 82: 7927.

11.- Miyashita N, Toyota E, Sawayama T, Matsumoto A, Mikami Y, Kawai N, et al. Association of chronic infection of Chlamydia pneumoniae and coronary heart disease in the Japanese. Intern Med 1998; 37: 913-6.

12.- Canul G, Vargas L, Laviada H. Los yucatecos: ¿De que se enferman y mueren? Cuad Nutr 1998; 21: 20-4.

13.- Arroyo P, Pardío L, Fernández V, Vargas L. Obesity and cultural environment in the Yucatan region. Nutr Rev 1999; 57:S78-S83.

14.- Laviada H, Vargas L, Arroyo P, Pardío J, Fernández V. Epidemiología de Diabetes Mellitus en la población urbana de Yucatán. Revista de Endocrinología y Nutrición 1999; 7 (Supl): 109.

15.- Valles V, Laviada H, Vargas L, Arroyo P, Fernández V, Pardío P. Epidemiología de dislipidemias en la población Urbana de Yucatán. Revista de Endocrinología y Nutrición 1999; 7 (Supl): 110. 